\title{
Risk factors related with high sodium intake among Malaysian adults: findings from the Malaysian Community Salt Survey (MyCoSS) 2017-2018
}

Nur Shahida Abdul Aziz ${ }^{1 *}$, Rashidah Ambak', Fatimah Othman', Feng J. He², Muslimah Yusof ${ }^{3}$, Faizah Paiwai', Suhaila Abdul Ghaffar', Muhammad Fadhli Mohd Yusof ${ }^{1}$, Siew Man Cheong ${ }^{1}$, Graham MacGregor ${ }^{2}$ and Tahir Aris ${ }^{1}$

\begin{abstract}
Background: High sodium intake was an established risk factor for stroke and cardiovascular diseases. The objective of this study was to investigate factors associated with high sodium intake based on 24-h urinary sodium excretion from the MyCoSS study.

Methods: The cross-sectional survey was conducted among adults aged 18 years and above in Malaysia. A multistage stratified sampling was used to represent nationally. Twenty-four-hour urine was collected from a total of 900 respondents. Indirect ion-selective electrode (ISE) method was used to measure sodium intake. Descriptive and logistic regression analysis was applied to determine factors associated with high sodium intake based on 24-h urinary sodium excretion.

Results: A total of 798 respondents (76\% response rate) completed the 24 -h urine collection process. Logistic regression revealed that high sodium intake associated with obese [aOR $2.611(95 \% \mathrm{Cl} 1.519$, 4.488)], male [aOR $2.436(95 \% \mathrm{Cl} 1.473,4.030)$ ], having a waist circumference of $>90 \mathrm{~cm}$ for adult males [aOR $2.260(95 \% \mathrm{Cl} 1.020$, $5.009)$ and $>80 \mathrm{~cm}$ for adult females [aOR $1.210(95 \% \mathrm{Cl} 0.556,2.631)$ ], being a young adult [aOR $1.977(95 \% \mathrm{Cl} 1.094$, 3.574)], and living in urban areas [aOR 1.701 (95\% Cl 1.094, 2.645)].

Conclusion: Adults who are obese, have a large waist circumference, of male gender, living in urban areas, and belonging to the young adult age group were found to have higher sodium intake than other demographic groups. Hence, reduction of salt consumption among these high-risk groups should be emphasised to reduce the risk of cardiovascular diseases.
\end{abstract}

Keywords: High sodium, Associated factors, Adults, Sodium intake, Malaysia, MyCoSS

\footnotetext{
* Correspondence: nshahida@moh.gov.my

${ }^{1}$ Institute for Public Health, National Institutes of Health, Ministry of Health Malaysia, Kuala Lumpur, Selangor, Malaysia

Full list of author information is available at the end of the article
}

(c) The Author(s). 2021 Open Access This article is licensed under a Creative Commons Attribution 4.0 International License, which permits use, sharing, adaptation, distribution and reproduction in any medium or format, as long as you give appropriate credit to the original author(s) and the source, provide a link to the Creative Commons licence, and indicate if changes were made. The images or other third party material in this article are included in the article's Creative Commons licence, unless indicated otherwise in a credit line to the material. If material is not included in the article's Creative Commons licence and your intended use is not permitted by statutory regulation or exceeds the permitted use, you will need to obtain permission directly from the copyright holder. To view a copy of this licence, visit http://creativecommons.org/licenses/by/4.0/ The Creative Commons Public Domain Dedication waiver (http://creativecommons.org/publicdomain/zero/1.0/) applies to the data made available in this article, unless otherwise stated in a credit line to the data. 


\section{Background}

Excessive sodium consumption is a leading cause of high blood pressure, which can lead to greater risk of stroke and cardiovascular disease (CVD) $[1,2]$. About $12.8 \%$ of all death globally was from high blood pressure [3]. Hence, based on the evidence of the beneficial effects of salt reduction, the World Health Organization (WHO) recommends a daily population intake for sodium of $<2.0 \mathrm{~g}$ per day (5 g per day of salt) [1].

Therefore, from a preventive medicine perspective, reducing the amount of sodium intake will help in reducing the level of blood pressure. Studies have shown lower sodium consumption was associated with lower systolic blood pressure(SBP) and diastolic blood pressure (DBP), and it could potentially reduce the prevalence of hypertension and other health consequences [4-6]. Moreover, risk reduction in stroke was $4.2 \%$ and $3.8 \%$ for myocardial infarction (MI) when systolic blood pressure is reduced by $2 \mathrm{mmHg}$ [7]. The Dietary Approach to Stop Hypertension (DASH) study showed that lowering sodium in diet had an even stronger impact on reducing blood pressure and this study contributed much of the scientific basis for the Dietary Guidelines for Americans 2015-2020. The guideline recommended less than a teaspoon of sodium per day [8]. However, there were several factors which lead to high sodium intake such as age, social, culture, education, and income level [9].

The 24-h urinary excretion test is a widely used and valid tool for assessing dietary sodium intake [10]. It is also known as the gold standard method for the assessment of urine excretion. Numerous studies found that most of the sodium consumed in a day (90 to 95\%) is excreted through urine in the next $24 \mathrm{~h}[11,12]$. Cogswell et al. (2018) studied 24-h sodium excretion and blood pressure within and across populations aged 20-59 years old and found that mean sodium excretion was higher in men (4205 mg) than in women (3039 mg) [5].

In the Malaysian context, a few studies have been carried out on sodium consumption for specific groups and found that sodium consumption is high among Malaysians and far exceeds the recommended values [13]. A study among Ministry of Health staff showed that sodium consumption exceeded $2000 \mathrm{mg} /$ day [14]. We aimed to investigate factors that are associated with high sodium intake based on 24-h urinary sodium excretion among a large, nationally representative sample of the adult population in Malaysia.

\section{Methods}

\section{Study design}

This is a cross-sectional household survey that applied a stratified cluster sampling method. to ensure national representativeness in Malaysia which included adults aged more than 18 years old. Data collection was conducted between October 2017 and March 2018. Details of MyCOSS's methodology are described in an article in the present journal supplement (Introduction to the Malaysian Community Salt Survey (MyCoSS): a population-based survey on salt intake to support salt reduction strategies in Malaysia). Respondents were given a patient information sheet (PIS) in Malay or English language to read prior to obtaining consent. Any queries about the study would be addressed by the study team. Written consent was obtained from all eligible respondents. Respondents who were found to have higher blood pressure or other abnormal results not previously diagnosed or investigated were referred to the nearest government clinic or hospital for further management. The respondents were informed the results of the physical examination, such as blood pressure, height, and weight, during data collection.

Sample size calculation used a formula for estimating population prevalence. The sample size calculation for determination of sodium intake referred to finding from salt study among health workers in Malaysia (My Salt 2015) [15]. Mean sodium of $142 \mathrm{mmol}$, relative standard error (RSE) of 0.05 , and design effect 1.5 , including $50 \%$ nonresponse, 816. Samples with no missing urine and more than $500 \mathrm{ml}$ were included in analysis. Respondents who were pregnant, suffering from chronic kidney failure, or undergoing dialysis were excluded from this study.

\section{Data collection}

The respondents were given both oral and printed instructions on how to accurately collect the urine. Twenty-fourhour urine collection was used as it was the gold standard for estimating sodium intake. Respondents were required to collect a single urine sample for $24 \mathrm{~h}$, in a 5-l urine container. Plastic cups were given to respondents to assist in collecting urine. They were instructed to discard the first urine void in the morning and collect all subsequent urine until the first urine void in the following morning. The last collection was the first urination on the second day of collection. They recorded the beginning and end of 24-h urine collection, and were asked to notify any missed collection to data collectors. Sodium was measured using the indirect ion-selective electrode (ISE) method [10]. Sodium intake (mg) in a day was calculated by multiplying 24-h urinary sodium excretion ( $\mathrm{mmol}$ ) with a factor of 23. Urine results were given to the respondents at the end of the study along with recommendations on reducing salt intake. Sodium intake was then compared to the Malaysian and WHO dietary sodium recommended intake of less than $2000 \mathrm{mg} /$ day.

\section{Statistical analysis}

Population estimates were made by weighting the age and sex specific estimates obtained from the survey 
using sample-to-population weights calculated using census data. Descriptive statistics of complex sample data was computed and mean sodium intake was compared within group of socio-demography and anthropometry characteristic. Significant $p$ values were at less than 0.05. Complex sample logistic regression analysis was used to determine the association between risk factors related with high sodium intake (defined as 24-h sodium excretion exceeding $2000 \mathrm{mg}$ /day). Crude odds ratios (cOR) were used to describe the strength of association between factors and high sodium intake. The adjusted OR (aOR), with $p$ value less than 0.05 , was considered significant in the full logistic regression model. All statistical analyses were conducted using SPSS version 21

\section{Results}

A total of 798 urine samples were collected from respondents. About $79 \%$ of the Malaysian population consumed sodium excessively in their diet. Table 1 shows the basic socio-demographic characteristics. Mean sodium intake was higher among respondents in urban areas (3252.3 $\mathrm{mg} /$ day) compared in rural areas. Based on gender, men (3519 mg/day) showed significantly higher sodium intake compared to women. Among age groups, younger adults $25-34$ years old $(3556 \mathrm{mg} /$ day) showed significantly higher sodium intake compared to other age groups. Besides that, never married/single (3389.7mg/day) had higher mean sodium intake as compared with other marital status while self-employed ( $3467.2 \mathrm{mg} /$ day) had higher mean sodium intake compared to other types of occupation. Meanwhile for nutritional status by BMI cut off points, obese respondents (3643.2 $\mathrm{mg} / \mathrm{l})$ had significantly higher mean sodium intake compared to other categories.

Logistic regression analysis showed high sodium intake was significantly associated with strata, gender, age group, waist circumference, and body mass index (Table 2). Specifically, being obese [aOR 2.611 (95\%CI 1.519 , 4.488)] and having a waist circumference $>90 \mathrm{~cm}$ for males [aOR 2.260 (95\%CI 1.020, 5.009)] and $>80 \mathrm{~cm}$ for females [aOR 1.210 (95\%CI 0.556, 2.631)] were significantly more likely to have high sodium intake. Besides, being male [aOR 2.436 (95\% CI 1.473, 4.030)], being young adults [aOR 1.977 (95\%CI 1.094, 3.574)], and living in urban areas [aOR 1.701 (95\% CI 1.094, 2.645)] were also more likely to have high sodium intake.

\section{Discussion}

Mean sodium intake in this study was $3167 \mathrm{mg}$ per day $(3167 \mathrm{mg} /$ day $=138 \mathrm{mmol} /$ day $=7.9 \mathrm{~g}$ salt $=1.6 \mathrm{tsp}$. $)$. Besides, high sodium intake was also seen in urban areas, among men and obese respondents. This finding showed that sodium intake among the Malaysian population was higher than the WHO's recommendation of less than $2000 \mathrm{mg} /$ day of sodium [1]. Similarly other countries such as the USA, the UK, Singapore, and Korea reported that their result of sodium intake based on 24-h urine sodium excretion was higher than the WHO's recommendation $[16,17]$.

Several studies have demonstrated evidence that high sodium intake was associated with an increased risk of obesity [12]. This is similar to findings in the present study where respondents with high body mass index (BMI) were more likely to have high sodium intake. This might be due to high consumption of high calorie foods, seasoning, sauces, or other junk foods. Most processed food products are known to have high sodium content as a preservative substance. Some studies have also revealed that consumption of salt enhanced foods has a direct association with obesity $[18,19]$. Eating salty food is also associated with an increase in sugar intake as the high sodium intake will induce feeling of thirst leading to increased fluid intake, especially sugar-sweetened beverages $[20,21]$.

The present study also shows that high sodium intake and a large waist circumference are positively associated [aOR=2.260 (male), 1.210 (female)], comparable to a similar study conducted in Brazil [22]. Respondents with high sodium intake may tend to have greater energy intake and unhealthy food intake which were associated with increased risk for being overweight and abdominal obesity. In addition, high sodium intake also has a strong association with increased BMI $[18,23]$.

In this study, salt intake was significantly higher among males (3519 mg/day) compared to females (2790 $\mathrm{mg} /$ day), which was similar with other studies $[4,12]$ that revealed males tend to have higher sodium intake [15]. This might be due to the differences in physical structure and calorie intake requirements between both sexes. This finding was also supported by another study that reported males consumed high sodium foods $10 \%$ more than females [24]. It may be possible that females are generally more concerned about their physical appearance and health, which compels them to make better and healthier food choices which tend to be less calorie-dense and low in sodium.

Findings from the present study also showed that sodium intake is influenced by age. Younger and middleaged adults between 18 and 40 years were found to have higher sodium intake than those aged 60 years and above. Similar findings from another study reported that adults aged 30-40 years old had a significantly higher sodium intake compared to other age groups [25-28]. It is also known that younger adults have a higher calorie intake and they mostly eat a wider variety of meals and snacks compared with the elderly [26, 27]. The elderly may have reason to control their sodium because of 
Table 1 Sodium intake (mg/day) by socio-demographic and anthropometric characteristics of respondents $(n=798)$

\begin{tabular}{|c|c|c|c|c|c|}
\hline & \multirow{3}{*}{$\begin{array}{l}\text { Unweighted } \\
\text { count }\end{array}$} & \multirow[t]{3}{*}{$\%$} & \multicolumn{3}{|c|}{ Sodium intake } \\
\hline & & & \multirow[t]{2}{*}{ Mean } & \multicolumn{2}{|l|}{$95 \% \mathrm{Cl}$} \\
\hline & & & & Lower & Upper \\
\hline Malaysia & 798 & 100.0 & 3166.7 & 2987.33 & 3346.10 \\
\hline \multicolumn{6}{|l|}{ Strata } \\
\hline Urban & 319 & 75.8 & 3252.3 & 3022.82 & 3481.82 \\
\hline Rural & 479 & 24.2 & 2895.9 & 2749.57 & 3042.16 \\
\hline \multicolumn{6}{|l|}{ Gender } \\
\hline Men & 340 & 51.7 & 3519.5 & 3210.00 & 3828.92 \\
\hline Women & 458 & 48.3 & 2789.2 & 2648.86 & 2929.52 \\
\hline \multicolumn{6}{|l|}{ Age groups (years) } \\
\hline $18-39$ & 235 & 29.4 & 3176.7 & 2983.54 & 3370.05 \\
\hline $40-59$ & 347 & 43.5 & 2985.1 & 2840.10 & 3130.11 \\
\hline $60+$ & 216 & 27.1 & 2823.2 & 2641.76 & 3004.56 \\
\hline \multicolumn{6}{|l|}{ Marital status } \\
\hline Never married & 93 & 11.5 & 3389.7 & 3021.73 & 3757.74 \\
\hline Married & 594 & 77.7 & 3057.2 & 2946.24 & 3168.20 \\
\hline Separated/widower & 110 & 2.5 & 2340.9 & 2154.02 & 2527.78 \\
\hline \multicolumn{6}{|l|}{ Education level } \\
\hline None & 64 & 5.1 & 2745.2 & 2125.37 & 3346.94 \\
\hline Primary & 167 & 18.2 & 3051.4 & 2666.83 & 3435.97 \\
\hline Secondary & 383 & 51.1 & 3234.6 & 2990.52 & 3478.77 \\
\hline Tertiary & 184 & 25.6 & 3207.0 & 2956.47 & 3457.44 \\
\hline \multicolumn{6}{|l|}{ Occupation } \\
\hline Public & 117 & 14.0 & 3324.7 & 2871.13 & 3778.40 \\
\hline Private & 126 & 17.2 & 3337.0 & 2989.19 & 3684.88 \\
\hline Self-employed & 179 & 23.0 & 3467.2 & 3036.29 & 3898.10 \\
\hline Housewives & 214 & 23.5 & 2903.6 & 2720.87 & 3086.43 \\
\hline Unemployed & 113 & 13.7 & 2887.2 & 2541.58 & 3243.01 \\
\hline Student & 15 & 2.0 & 2919.6 & 2182.25 & 3653.12 \\
\hline Others & 34 & 6.6 & 2919.4 & 2425.44 & 3409.36 \\
\hline \multicolumn{6}{|c|}{ Body mass index $\left(\mathrm{kg} / \mathrm{m}^{2}\right)$} \\
\hline Underweight & 35 & 4.5 & 2028.5 & 1697.20 & 2359.88 \\
\hline Normal & 285 & 35.2 & 2878.0 & 2672.62 & 3083.47 \\
\hline Overweight & 287 & 37.5 & 3283.2 & 3005.98 & 3560.45 \\
\hline Obese & 191 & 22.8 & 3643.2 & 3216.13 & 4070.86 \\
\hline \multicolumn{6}{|c|}{ Waist circumference (cm) } \\
\hline Men $<90$ & 166 & 34.7 & 3033.3 & 2767.10 & 3299.55 \\
\hline Men $\geq 90$ & 174 & 65.3 & 3901.0 & 3450.85 & 4351.17 \\
\hline Women $<80$ & 180 & 39.3 & 2462.1 & 2192.16 & 2732.22 \\
\hline Women $\geq 80$ & 618 & 60.7 & 2887.2 & 2887.21 & 3046.36 \\
\hline
\end{tabular}

illness or they may just be more health-conscious [2931]. This finding may guide intervention efforts in salt reduction to focus upon at-risk populations in terms of highest sodium intake.
This study also revealed that respondents living in urban areas were more likely to have high sodium intake. Similar findings of such differences between urban and rural regions were also reported in Ethiopia and 
Table 2 Factors associated with high sodium intake among Malaysian adults ( $n=798$ )

\begin{tabular}{|c|c|c|c|c|c|c|c|c|}
\hline \multirow{3}{*}{$\begin{array}{l}\text { Study } \\
\text { characteristic }\end{array}$} & \multicolumn{3}{|c|}{ Unadjusted } & \multirow[t]{3}{*}{$p$ value } & \multicolumn{3}{|l|}{ Adjusted } & \multirow[t]{3}{*}{$p$ value } \\
\hline & \multirow{2}{*}{$\begin{array}{l}\text { Crude } \\
\text { OR }\end{array}$} & \multicolumn{2}{|l|}{$95 \% \mathrm{Cl}$} & & \multirow{2}{*}{$\begin{array}{l}\text { Adjusted } \\
\text { OR }\end{array}$} & \multicolumn{2}{|l|}{$95 \% \mathrm{Cl}$} & \\
\hline & & Lower & Upper & & & Lower & Upper & \\
\hline \multicolumn{9}{|l|}{ Strata } \\
\hline Urban & 1.730 & 1.198 & 2.499 & 0.039 & 1.701 & 1.094 & 2.645 & $0.017^{*}$ \\
\hline Rural & 1 & - & - & & 1 & - & - & \\
\hline \multicolumn{9}{|l|}{ Gender } \\
\hline Men & 2.013 & 1.183 & 3.426 & $<0.001$ & 2.436 & 1.473 & 4.030 & $<0.001^{*}$ \\
\hline Women & 1 & - & - & & 1 & - & - & \\
\hline \multicolumn{9}{|c|}{ Age groups (years) } \\
\hline 18-39 & 1.588 & 0.889 & 2.835 & 0.027 & 1.977 & 1.094 & 3.574 & $0.010^{*}$ \\
\hline $40-59$ & 1.707 & 1.006 & 2.897 & 0.045 & 1.871 & 1.136 & 3.081 & $0.043^{*}$ \\
\hline $60+$ & 1 & - & - & & 1 & - & - & \\
\hline \multicolumn{9}{|c|}{ Body mass index $\left(\mathrm{kg} / \mathrm{m}^{2}\right)$} \\
\hline Underweight & 0.347 & 0.138 & 0.874 & 0.078 & 0.2281 & 0.071 & 0.726 & 0.107 \\
\hline Normal & 1 & - & - & & 1 & - & - & \\
\hline Overweight & 22.106 & 1.344 & 3.300 & $<0.001$ & 1.890 & 1.111 & 3.214 & $0.007^{*}$ \\
\hline Obese & 2.659 & 1.619 & 4.368 & $<0.001$ & 2.611 & 1.519 & 4.488 & $<0.001^{*}$ \\
\hline \multicolumn{9}{|c|}{ Waist circumference $(\mathrm{cm})$} \\
\hline Men <90 & 1 & - & - & & 1 & - & - & \\
\hline Men >90 & 2.311 & 0.998 & 5.353 & 0.018 & 2.260 & 1.020 & 5.009 & $<0.001^{*}$ \\
\hline Women $<80$ & 1 & - & - & & 1 & - & - & \\
\hline Women $\geq 80$ & 1.597 & 0.860 & 2.967 & 0.045 & 1.210 & 0.556 & 2.631 & $0.049^{*}$ \\
\hline
\end{tabular}

*Significance at $p$ value $<0.05$

India [27]. The ubiquity of and easy accessibility to fast food restaurants, as well as busier lifestyles that allow less time for cooking healthy low-salt meals at home, were among factors contributing to higher sodium intake [32-34].

To our knowledge, this is the first large-scale survey on sodium intake done in Malaysia in a community setting. However, we were not able to evaluate causality due to the cross-sectional design. Another limitation is that data on drug histories or other dietary components that might affect urinary sodium excretion were not available. Collection of 24-h urine is labour intensive, with low response rates and sample rejection due to missing urine creating potential for bias.

\section{Conclusions}

In summary, the identification of certain sociodemographic factors such as age, sex, locality, BMI, and waist circumference that are strongly associated with high sodium intake provides important information to be taken into consideration in developing interventions for reducing sodium intake among the Malaysian population.

\section{Abbreviations}

BMI: Body mass index; ISE: Ion selective electrode; SBP: Systolic blood pressure; DBP: Diastolic blood pressure; aOR: Adjusted odds ratio; OR: Odds ratio; WHO: World Health Organization; DASH: Dietary Approaches to Stop Hypertension

\section{Acknowledgements}

The authors would like to thank the Director General of Health Malaysia for permission to publish this paper. Acknowledgement also goes to Department of Statistics, Malaysia, in the Ministry of Health Malaysia (Nutrition Division, Non-Communicable Disease Section, State Health Departments, Liaison Officers and Scouts) in the preparation and during the data collection. We also thank all individuals who directly or indirectly contributed to the success of this study.

\section{About this supplement}

This article has been published as part of Journal of Health, Population and Nutrition Volume 40 Supplement 1, 2021: Malaysian Community Salt Survey 2017-2018 (MyCoSS). The full contents of the supplement are available online at https://jhpn.biomedcentral.com/articles/supplements/volume-40supplement-1.

\section{Authors' contributions}

RA, NSAA, FJH, FO, GMG, MFMY, and TA were responsible for the concept and project development. RA and FO supervised the project's progress. NSAA performed the statistical analysis and drafted the manuscript. MY, SAG, FP, and CSM contributed to review and editing of the manuscript. All authors have read and approved the final manuscript. 


\section{Funding}

Publication costs are funded by the Newton-Ungku Omar Fund: UK Malaysia Bilateral Health Research Collaboration for Non-Communicable Diseases with the grant number of MR/P012590/1 (joint funding from the Academy of Sciences Malaysia, Malaysian Industry-Government Group for High Technology, and the Medical Research Council, UK). The funders had no role in the study design, data collection, data analysis, data interpretation, or writing of the article.

\section{Availability of data and materials}

The datasets used and/or analysed during the current study are available from the corresponding author on reasonable requests.

\section{Declarations}

Ethics approval and consent to participate

Ethical approvals for the study were obtained from the Medical Research Ethics Committee (MREC), Ministry of Health Malaysia (NMRR-17-423-34969), and Queen Mary (University of London) Research Ethics Committee (QMER C2017/14) prior to conducting the study. Informed written consent was collected from all respondents at the beginning of the study.

\section{Consent for publication}

Not applicable.

\section{Competing interests}

The authors declare that they have no competing interests.

\section{Author details}

${ }^{1}$ Institute for Public Health, National Institutes of Health, Ministry of Health Malaysia, Kuala Lumpur, Selangor, Malaysia. ${ }^{2}$ Wolfson Institute of Preventive Medicine, London School of Medicine \& Dentistry, Queen Mary University of London, London, UK. ${ }^{3}$ Paediatric Department, Women and Children Hospital, Kuala Lumpur, Malaysia.

Published: 31 May 2021

\section{References}

1. WHO. Global status report on non-communicable diseases. 2014

2. Strazzullo P, D'Elia L, Kandala NB, Cappuccio FP. Salt intake, stroke, and cardiovascular disease: meta-analysis of prospective studies. BMJ. 2009;339: b4567.

3. Webster UL, Dunford EK, Hawkes C, Neal BC. Salt reduction initiatives around the world. J Hypertens. 2011;29(6):1043-50.

4. Batcagan-Abueg APM, Lee JJ, Chan P, Rebello SA, Amarra MSV. Salt intakes and salt reduction initiatives in Southeast Asia: a review. Asia Pac J Clin Nutr. 2013:22(4):683-97.

5. Cogswell ME, Loria CM, Terry AL, Zhao L, Wang CY, Chen TC, et al. Estimated 24-hour urinary sodium and potassium excretion in US adults. JAMA. 2018;319(12):1-12.

6. Papadakis S, Pipe AL, Moroz IA, Reid RD, Blanchard CM, Cote DF, et al. Knowledge, attitudes and behaviour related to dietary sodium among 35 to 50 years old Ontario Residents. Can J Cardiol. 2010;26(5):e164-9.

7. Homan TD, Bordes S, Cichowski E. Physiology, Pulse Pressure. [Updated 2020 Jun 7]. In: StatPearls. Treasure Island: StatPearls Publishing; 2020. Available from: https://www.ncbi.nlm.nih.gov/books/NBK482408/. Access date 7 June 2020

8. Selmer RM, Kristiansen IS, Haglerød A, Graff-Iversen S, Larsen HK, Meyer HE, et al. Cost and health consequences of reducing the population intake of salt. J Epidemiol Community Health. 2000;54:697-702.

9. Bazzano LA, Green T, Harrison TN, Reynolds K. Dietary approaches to prevent hypertension. Curr Hypertens Rep. 2013;15(6):694-702.

10. Lallukka T, Laaksonen M, Rahkonen O, Roos E, Lahelma E. Multiple socioeconomic circumstances and healthy food habits. Eur J Clin Nutr. 2007; 61(6):701-10.

11. Land M-A, Webster J, Christoforou A, Praveen D, Jeffery P, Chalmers J, et al. Salt intake assessed by $24 \mathrm{~h}$ urinary sodium excretion in a random and opportunistic sample in Australia. BMJ Open. 2014;4:e003720.

12. Sauvageot N, Alkerwi A, Albert A, Guillaume M. Use of food frequency questionnaire to assess relationship between dietary habits and cardiovascular risk factors in NESCAV study:validation with biomarkers. Nutr J. 2013;12(1):143

13. Leiba A, Vald A, Peleg E, Shamiss A, Grossman E. Does dietary recall adequately assess sodium, pottassium and calcium intake in hypertensive patients? Nutrition. 2005;21(4):462-6.

14. Maryam K, Nani N, Rahman AR. 1048 Correlation between spot urine sodium, 24 hour urinary sodium and food frequency questionaire in estimation of salt intake in healthy individuals. J Hypertension. 2012;30:e305.

15. Institute for Public Health (IPH) 2016. Determination of dietary sodium intake among the Ministry of Health staff 2015 (MySalt 2015).

16. Rashidah A, Yeo PS, Noor Ani A, Muhammad Fadhli MY, Tahir A, et al. Sodium intake among normotensive health staff assessed by 24-hours urine excretion: a cross-sectional study. Malays J Nutr. 2014;20(3):317-26.

17. Hong JW, Jung HN, Dong JK. Factors associated with high sodium intake based on estimated 24-hour urinary sodium excretion: the 2009-2011 Korea National Health and Nutrition Examination Survey. Medicine. 2016;95(9).

18. Huang L, Crino M, Wu JH, Woodward M, Barzi F, Land MA, et al. Mean population salt intake estimated from 24-h urine samples and spot urine samples: a systematic review and meta-analysis. Int J Epidemiol. 2016;45(1):239-50.

19. Nerbass FB, Pecoits-Filho R, McIntyre NJ, Mclntyre CW, Willingham FC, Taal MW. Demographic association of high estimated sodium intake and frequency of consumption of high-sodium foods in people with chronic kidney disease stage 3 in England. J Ren Nutr. 2014;24(4):236-42.

20. Hin SL, Khor WH. Influence of food intake and eating habits on hypertension control among outpatients at government health clinic in Klang Valley, Malaysia. Malays J Nutr. 2011;17(2):163-73.

21. He FJ, Markandu ND, Sagnella GA, McGregor GA. Effect of salt intake on renal excretion of water in humans. Hypertension. 2001;38:317-20.

22. Grimes CA, Riddell $\sqcup$, Campbell K, Nowson CA. Dietary salt intake, sugarysweetened beverage consumption and obesity risk. Pediatrics. 2013;131(1):14-21.

23. Dos Santos EM, Brito DJDA, Calado IL, Franca AKT, Lages JS, Monteiro Junior FDC, et al. Sodium excretion and associated factors in urine samples of African descendants in Alcântara, Brazil: a population based study. Ren Fail. 2018;40(1):22-9

24. Navia B, Aparicio A, Perea JM, Perez-Farinoz N, Villar-Vilalba C, Labrado E, et al. Sodium intake may promote weight gain; results of the FANPE study in a representative sample of the adults Spanish population. Nutr Hosp. 2014;29:1283-9.

25. Powles J, Fahimi S, Micha R, et al. Global, regional and national sodium intakes in 1990 and 2010: a systematic analysis of $24 \mathrm{~h}$ urinary sodium excretion and dietary surveys worldwide. BMJ Open. 2013;3:e003733.

26. Kamran A, Azadbakht L, Sharifirad G, Mahaki B, Sharghi A. Sodium intake, dietary knowledge, and illness perceptions of controlled and uncontrolled rural hypertensive patients. Int J Hypertens. 2014;2014:245480.

27. James D. Factors influencing food choices, dietary intake and nutritionrelated attitudes among African Americans:Application of culturally sensitive model. Ethn Health. 2004;9(4):349-67.

28. Yang Q, Liu T, Kuklina EV, Flanders WD, Hong Y, Gillespie C, et al. Sodium and potassium intake and mortality among US adults: prospective data from the Third National Health and Nutrition Examination Survey. Arch Intern Med. 2011;171(13):1183-91.

29. Challa F, Tadesse F, Mudie K, Taye G, Gelibo T, Bekele A, Sileshi M, et al. Urinary sodium excretion and determinates among adults in Ethiopia: Findings from National STEPS survey. Ethiop J Health Dev. 2017;31(1):370-7.

30. Hasenegger $V$, Rust $P$, König J, Purtscher $A E$, Erler J, Ekmekcioglu C. Main sources, socio-demographic and anthropometric correlates of salt intake in Austria. Nutrients. 2018:10(3):311.

31. University of Helsinki. Salt intake is strongly associated with obesity. ScienceDaily. ScienceDaily, 13 November 2006. www.sciencedaily.com/relea ses/2006/11/061101151027.htm. Accessed 23 Oct 2018.

32. Ma Y, He FJ, MacGregor GA. High salt intake: independent risk factor for obesity? Hypertension. 2015;66(4):843-9.

33. Dhelma S, Varma K. Salt intake in India- an alarming situation. Int J Food Agric and Vet Sci. 2015;5:1-0.

34. Misra A, Singhal N, Sivakumar B, Bhagat N, Jaiswal A, Khurana L. Nutrition transition in India: secular trends in dietary intake and their relationship to diet-related non-communicable diseases. J Diabetes. 2011;3:278-92.

\section{Publisher's Note}

Springer Nature remains neutral with regard to jurisdictional claims in published maps and institutional affiliations. 